\title{
The loss of first language phonetic perception in adopted Koreans
}

\author{
Valérie A. G. Ventureyra \\ Laboratoire de Sciences Cognitives et Psycholinguistique, EHESS-CNRS, 54 bd Raspail, Paris, France, 75006 \\ Christophe Pallier \\ Hi-Yon Yoo \\ Unité de Neuroimagerie Cognitive, Inserm U562, SHFJ \& Atelier de Recherche sur la Parole, UFR de Linguistique, \\ IFR49, 4 pl. du Général Leclerc, Orsay, France, 91401. Université Paris VII, 2 place Jussieu, Paris, France, 75005.
}

\section{[Note: This is a preprint of a paper accepted for publication in Journal of Neurolinguistics. Check http://www.pallier.org/papers for the updated list of publications by C. Pallier]}

\begin{abstract}
Does early exposure to a language leave permanent traces in the brain? We examine this issue by testing a group of native Koreans who were adopted by French-speaking families and have stopped using their first language for many years. Previous results suggest that they are not able to recognize Korean sentences, nor to identify Korean words (Pallier et al. 2003). In the present study, we focus on the possible remnants of L1 phonology, by assessing the adoptees' capacity to discriminate Korean voiceless consonants which are difficult to perceive by native French speakers. Data from groups of adoptees, native speakers of French, and native speakers of Korean, show that the adoptees do not perceive the differences between Korean phonemes better than native French speakers previously unexposed to Korean. Also, adoptees having been reexposed to Korean and those without reexposure perform similarly on this task. These results demonstrate that the Korean adoptees do not have easy access to the phonetic categories of the Korean language.
\end{abstract}

A fi rst language can occasionally come into disuse (undergo attrition) during childhood. Some longitudinal studies in children have documented the process of attrition over several weeks or months. Nicoladis \& Grabois (2002) studied the simultaneous loss of Cantonese and acquisition of English in a young Chinese girl adopted by an English-speaking family in Canada, at age 17 months. The interactions with native Cantonese speakers over the three months following the child's arrival in Canada, revealed a rapid loss in both production and comprehension of this language by the child. Kaufman \& Aronoff (1991) studied a native Hebrewspeaking child having immigrated to the United States with her family at age $2 ; 6$. This child, contrary to the adoptees in the present study and the Chinese girl mentioned above, continued being exposed to her L1 while acquiring L2 in the school environment. Yet, despite this continued exposure, attrition of L1 (lexical and morphological) was once again observed after only a few months in the country of immigration. Turian \& Altenberg's (1991) study focussed on a Russian-English bilingual child whose exposure to Russian

Corresponding author: Val'erie Ventureyra, LSCP, EHESS, 54 bd Raspail, 75006 Paris, France. Email : valven@1scp.ehess.fr and pallier@1scp.ehess.fr; Fax : 331454498 35. Val'erie Ventureyra and Christophe Pallier contributed equally to this project, which was supported by an ACI Grant from the Ministère des Affaires 'etrangères to C.P.. We thank Chongdok Kim and Hui-Youn Son their help in recording the stimuli, and Narly Golestani for helpful comments on the manuscript
(L1) was radically reduced at age 3;6. Observation of the child's L1 conversational skills almost one year after the reduction in L1 input revealed several compensatory strategies and other elements of language attrition.

In spite of the insights offered by these case studies in children undergoing attrition, very little is known about the remains of this 'lost' language in adulthood. First language attrition studies in adults tend to focus on immigrants immersed in an L2 environment fairly late in life (Kopke, 2001; De Bot et al., 1991 and several other studies in Seliger \& Vago, 1991) and generally seek to evaluate the profi ciency of L1 through tasks requiring a relatively good command of the language (grammatical judgements, interviews, elicited narratives). These and other studies (Ammerlaan, 1996; Hulsen, 2000) in adults have found some evidence for attrition such as lexical retrieval diffi culties, errors in syntax and even in productive phonology (Major, 1992), but compared with the extensive attrition apparent in children such evidence is minimal. The discrepancy in nature and extent between child and adult L1 loss may be indicative of different mechanisms responsible for attrition according to age of onset.

In the present study we are interested in cases of foreign adoption. Individuals having undergone L1 attrition under such circumstances claim to have completely forgotten their L1 (Maury, 1999) and so any trace of L1 in childhood attriters can be expected to be rather subtle, maybe even unconscious. The methods required to reveal remnants of L1 in such subjects will therefore be quite different from those used to evaluate language in other cases of attrition.

The way in which speech is perceived depends on the lan- 
guage of the listener (see Pallier, Christophe \& Mehler, 1997 for a review). In particular, utterances are decoded into the vowel and consonant categories of the native language, and non-native phonetic contrasts are often diffi cult to perceive (Strange \& Jenkins, 1978 ; Polka, 1991). Language acquisition research has demonstrated that the attunement to the phonemes of the native language takes place during the fi rst year of life: by age 10 to 12 months, infants are already less sensitive to non-native phonetic contrasts than to native contrasts (Werker \&Tees, 1983, 1984 ; Kuhl et al., 1992). This decrease in sensitivity is a fi rst step in the reorganization of speech perception in favour of L1, which continues to occur throughout child development. It appears, then, that early linguistic experience shapes the way speech will be processed throughout life. However, not very much is known about the sensitivity to phonemes heard only in infancy or early childhood. Could this sensitivity be conserved through to adulthood?

To our knowledge only three studies have addressed the issue of remnants of the phonology of a language heard during early childhood (Tees \& Werker, 1984 ; Au et al., 2002 ; Oh et al., 2003). They suggest that some aspects of a language spoken or overheard during childhood and subsequently left in disuse subsist in adult relearners of the language. The fi rst of these studies (Tees \& Werker, 1984) involved Englishspeaking adults having been regularly exposed to Hindi during the fi rst year or two of life (by having either lived in India or by having lived with a Hindi-speaking relative during this time period) and relearning this language in adulthood. Ten early-exposure learners of Hindi and eighteen fi rst-time learners of Hindi were tested on a category-change discrimination task involving a retroflex-dental contrast characteristic of Hindi, place of articulation being the main distinctive feature of this contrast. The early-exposed subjects showed an advantage in the discrimination of the contrast relative to fi rst-time learners of Hindi. The two other studies, involving childhood overhearers of Spanish (Au et al., 2002) and childhood speakers/ overhearers of Korean (Oh et al., 2003), also found benefi ts of early linguistic input in relearners of the languages in question.

In the study by Au and colleagues, eleven participants had been exposed to several hours of Spanish per week for at least three years between birth and age 6 . The exposure to Spanish became less frequent thereafter and up until age 14, when the subjects started receiving formal instruction in this language. Twelve late learners of Spanish and ten native speakers of Spanish participated as well. Subjects from both the early-exposure and fi rst-time learner groups were currently enrolled in Spanish classes at university. The subjects' pronunciation of Spanish was evaluated: 1.) by an acoustic measurement (voice onset time: VOT, which is typically longer for stop consonants in English than in Spanish), 2.) by the application of a phonological rule : the spirantization (partial blocking of the air flow) of intervocalic stop consonants, and 3.) by accent ratings by native Spanish-speakers. The earlyexposed subjects performed in a more Spanish-like fashion than the late L2 learners on all of these criteria.

Oh et al.'s study involved 21 adult relearners of Korean having overheard or spoken Korean during childhood, ten fi rst-time learners of Korean and twelve native speakers of Korean. (The early-exposed subjects and the novice learners were both enrolled in fi rst-year university Korean language classes and were tested after four months of instruction.) The authors evaluated the subjects' perception of Korean consonants, and their production, with measurements of VOTs and accent ratings. In the phoneme perception task, subjects fi rst heard a word from a minimal triplet (three words varying only on the first consonant) and were then required to identify the heard word among the three words presented on a computer screen. On this task, both the childhood overhearers and speakers were found to be better than fi rst-time learners and performed similarly to native Koreans. In the phoneme production task, subjects read words from minimal triplets presented in random order and VOT measurements of the target consonants were made. The authors found that the childhood speakers produced VOTs like those of the native Koreans and were signifi cantly better than the overhearers and novice learners on this measure.

These studies point to an advantage of early linguistic exposure and suggest that prolonged lack of exposure may not result in a loss of early-acquired phonological abilities. The participants in these studies, however, either came from immigrant communities or grew up in communities where the attrited language was used. Moreover, in the latter two studies, subjects had been taking a course in the attrited language prior to testing (for several months up to fi ve years). It would therefore be interesting to know whether the fi ndings of remnants of phonology also apply to more extreme cases of language attrition such as that of foreign adoptees not reexposed to $\mathrm{L} 1$ since their adoption.

In the present study, we assess the perception of L1 phonemic contrasts in a population of eighteen Korean adoptees. This study follows up on the results of a previous one involving eight adult Koreans adopted during childhood (between 3 and 8 years of age) by French families (Pallier et al., 2003). In this study, Pallier and colleagues attempted to reveal traces of L1 in individuals having been completely cut-off and not reexposed to Korean since their arrival in France, fi fteen to twenty years prior to testing. These subjects claimed to have no knowledge of their L1. Behavioural tests (sentence identifi cation of Korean vs different languages, word recognition, fragment detection) comparing the Korean adoptees to a control group of native French speakers, did not reveal any differences between the groups. The authors also used functional Magnetic Resonance Imaging (fMRI) to monitor brain activations while the participants listened to sentences in French, Korean and two other unknown languages. None of the adoptees showed any activation specifi c to Korean relative to the unknown languages, and their pattern of activa-

\footnotetext{
${ }^{1}$ Voice Onset Time refers to the time from the release of a stop consonant to the onset of voicing of the following vowel.

${ }^{2}$ Korean uses a three-way contrast for its stop consonants. An important acoustical feature is VOT. (See Method for a more thorough description.) Oh et al. used Korean dental-alveloar stop consonants
} 
tion with French sentences was quite similar to that of the native French speakers. Hence, this study showed no evidence of remnants of $\mathrm{L} 1$ in the adoptees.

The above-mentioned studies of childhood overhearers of a language give reason to believe that remnants of phonology in perception may be available, perhaps at an unconscious level, in our population of adoptees, who were monolingual speakers of Korean before adoption. We tested this possibility with a phonetic discrimination task ${ }^{3}$ involving a threeway VOT contrast in Korean and compared the results of the adoptees with those of native Koreans and of monolingual French speakers.

\section{Method}

\section{Subjects.}

Eighteen Korean adoptees ( 7 women and 11 men) raised by French-speaking families in France, Switzerland or Belgium participated in this study. They were recruited with the help of an adoption agency in France (Terre des Hommes) and through an association for Korean adoptees (Racines Coréennes). These individuals were between 22 and 36 years of age $(M=29.2, S D=4.5)$ and had 0 to 6 years of education after high school $(\mathrm{M}=3.1, \mathrm{SD}=1.7)$. Their ages of adoption were distributed between 3 and 9 years $(M=5.8, S D=1.8$, see Figure 1). Nine of them had not been reexposed to Korean since adoption and nine others had been to Korea in the past four years for a stay of 10 days to 6 months.

Two control groups included twelve native French speakers ( 9 women and 3 men, aged between 19 and 42 years, $\mathrm{M}=27.6, \mathrm{SD}=6.4$ ) and twelve native Koreans (9 women and 3 men, aged between 26 and 43 years, $\mathrm{M}=31.9, \mathrm{SD}=5.2$ ). The French speakers had 0 to 5 years of education beyond high school $(\mathrm{M}=2.6, \mathrm{SD}=1.8)$. The native Korean subjects had 2 to 6 years of education beyond high school $(M=4.6$, $\mathrm{SD}=1.3)$. The Koreans were all from Seoul or the surrounding areas, and were mostly students residing in France (M= 3.4 years, $\mathrm{SD}=2.4$ ).

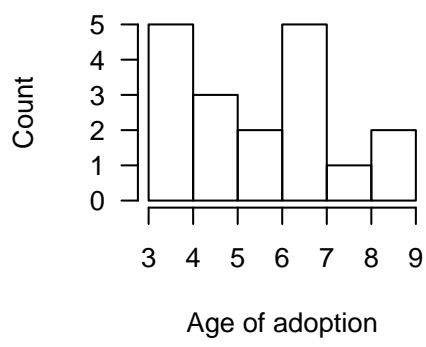

Figure 1. Distribution of ages of adoption in the sample of 18 Korean adoptees

Materials.
Korean consonants In Korean, each voiceless stop consonant ( $\mathrm{p}, \mathrm{t}$ or $\mathrm{k}$ ) can be produced in three ways that differ in laryngeal activity and the timing of laryngeal activity relative to supralaryngeal articulation. The main acoustical correlate of these manners of articulation is voice onset time (VOT) and the three types of consonants are named tense, plain and aspirated, in the order of increasing VOTs (see Figure 2). In Seoul and its surrounding areas a two-way contrast plain vs. tense is also used to distinguish two /s/ phonemes.
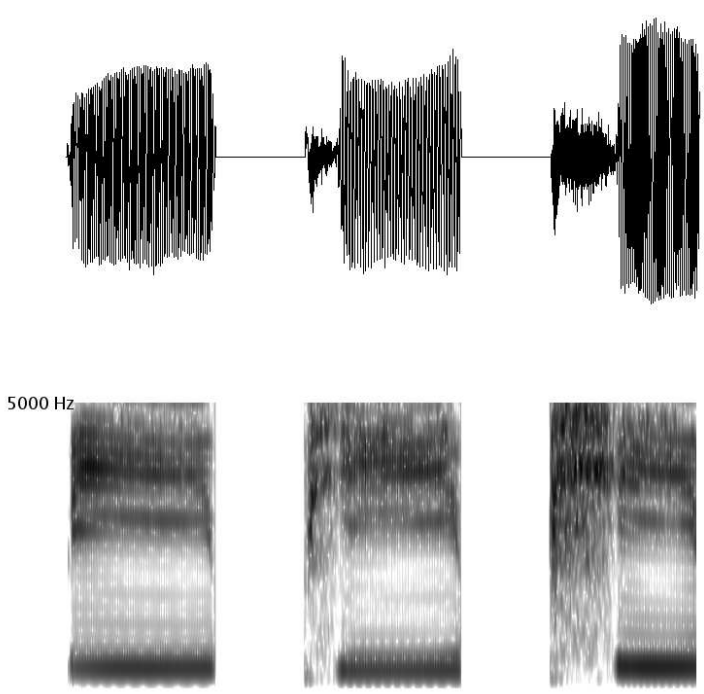

Figure 2. Spectrograms of three syllables differing in the first consonant. From left to right : tense, plain and aspirated /

Stimuli Twenty-four CVCV Korean pseudowords were created with the fi rst syllable always starting with a consonant characteristic of Korean : plain, tense or aspirated [k] or [p] or a plain or tense [s], followed by one of the following vowels : [a], [i] or [u] (each type of consonant co-occurred with each vowel). The second syllable was always [ma]. The pseudowords were recorded by two native speakers of the Seoul dialect of Korean (one woman and one man). The recordings were made in a sound-proof booth, low-pass fi 1tered at $20 \mathrm{Khz}$ and sampled at 16 bits/64 Khz. The pseudowords were excised and saved in different fi les; their mean duration was $644 \mathrm{msec}(\mathrm{SD}=78 \mathrm{msec})$.

We used these 24 pseudowords to create 138 pairs. The fi rst pseudoword was always produced by the male speaker and the second by the female speaker. In 48 pairs, the pseudowords were the same (condition $\mathrm{P}$ ) and in 48 other pairs, they differed in the first vowel (condition "DV"). The remaining pairs involved a difference in the first consonant: 12 pairs included a plain-tense contrast (condition DC1), 12 pairs included a plain-aspirated contrast (DC2), and 12 pairs

\footnotetext{
${ }^{3}$ The phonetic discrimination task is one of several behavioural experiments in a larger study seeking to reveal any possible traces of Korean in the adoptees.
} 
included a tense-aspirated contrast (DC3); these 36 pairs contrasted the $/ \mathrm{p} /$ and $/ \mathrm{k} /$ sounds. The last 6 pairs included a plain-tense contrast with the sound /s/ (condition DS).

Pretesting with four native Korean informants revealed that 3 pairs of stimuli (one from the DC1 condition and 2 from the DS condition) were not properly identifi ed as different and were thus excluded from the analyses.

Procedure.

The experiment was performed on a Dell Latitude C500, using the Presentation software from Neurobehavioral Systems. The stimuli were presented through headphones (SONY MDR-CD270) and responses made by clicking on mouse buttons. The task was a phoneme discrimination in which the subjects were required to determine whether two stimuli were identical in terms of category (as opposed to being physically identical). Subjects began with a training session using 12 pairs of pseudowords of French which differed in either the fi rst consonant or the fi rst vowel. The 138 pairs of Korean pseudowords were then presented, in random order. The second stimulus in a pair appeared $500 \mathrm{~ms}$ after the fi rst. A 1 second delay separated the subject's response from the beginning of the following trial. Subjects were required to indicate whether the two words of the pair were same or different by pressing a given button on the mouse (left=same, right=different) as quickly and accurately as possible. At the beginning of the experiment, subjects were reminded that Korean phonemes differed from French phonemes.

\section{Results}

The number of " different " responses in the various categories (DC1, DC2, DC3, DS, DV, P) was computed for each subject. Figure 3 shows the data averaged by groups, and Figure 4 shows the distributions of individual data.

An analysis of variance with the between-subjects variable Group ( $\mathrm{A}=$ adoptees, $\mathrm{F}=$ French, $\mathrm{K}=$ Korean), and the within-subject variable Category yielded signifi cant main effects of Group $(\mathrm{F}(2,39)=123, p<.001)$, and Category $(\mathrm{F}(5,195)=285 ; p<.001)$ as well as a signifi cant Group by Category interaction $(\mathrm{F}(10,195)=55 ; p<.001)$.

As Figure 3 reveals, the native Korean group gave markedly different responses from the other two groups; they performed signifi cantly better in the consonant contrast conditions (DC1, DC2, DC3, DS). To test for any difference between the French and adoptee groups, we compared their scores on each category using t-tests. None of the comparisons revealed a signifi cant effect, though the advantage of the adoptees in the DC1 category was marginally signifi cant $(4.5 \%, \mathrm{t}(28)=1.8, p<.1)$.

Tests on collapsed scores for the adoptee and French subjects, comparing the categories, revealed that the performance on the DC1 category (4\%) was signifi cantly poorer than that on the DC2 (22\%) and DC3 (22\%) categories $(\mathrm{t}(29)=5,6, p<.001$ and $\mathrm{t}(29)=4.9 p<.001$, respectively).

As is apparent in Figure 4, the DC2, DC3 and DS categories received a wider range of scores than the other categories. On the DC3 category, it is also worth noting that one adoptee's score is close to $80 \%$.

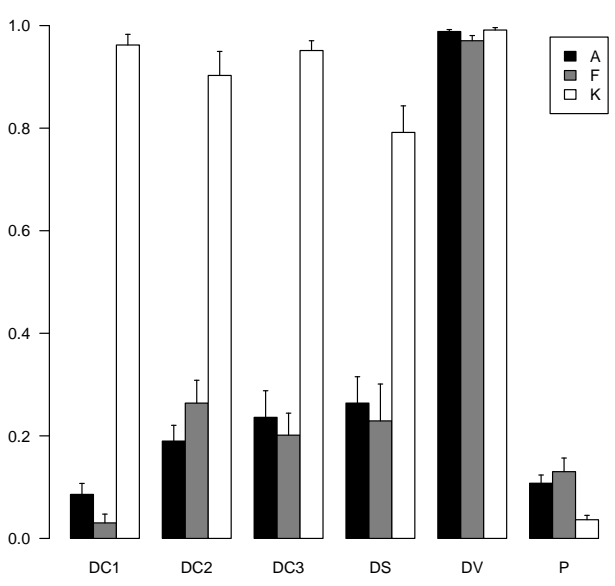

Figure 3. Results of the Phonetic Discrimination task for three groups of subjects $(\mathrm{A}=$ adoptees, $\mathrm{F}=$ French native speakers, $\mathrm{K}=$ Korean native speakers) expressed as percentage of different responses per category of contrast. (DC1=plain-tense contrast for $\mathrm{p}$ and $\mathrm{k}(11)$; DC2=plain-aspirated $\mathrm{p}$ and $\mathrm{k}(12) ; \mathrm{DC} 3=$ tense-aspirated $\mathrm{p}$ and $\mathrm{k}$ (12); DS=plain-tense s (4); DV=vowel contrast (48) and $\mathrm{P}=\mathrm{Same}(48)$ ).

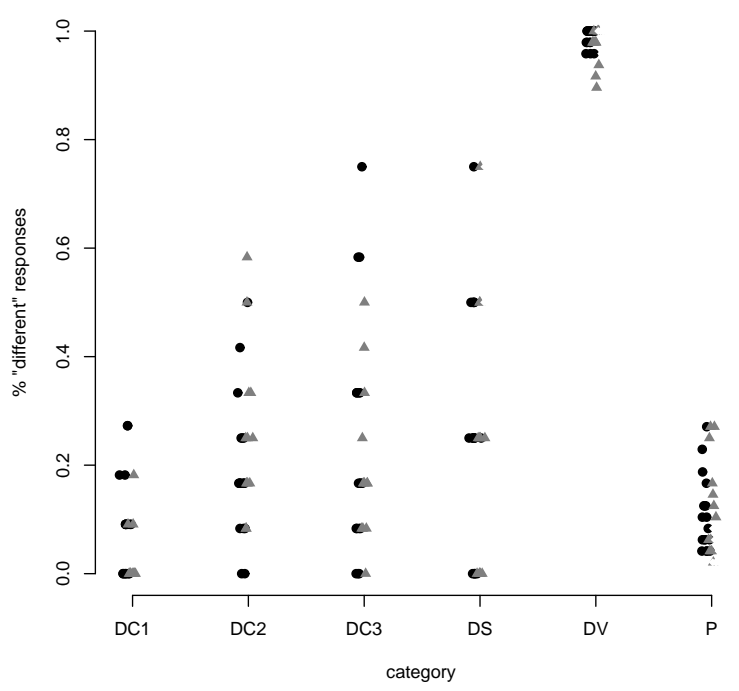

Figure 4. Distributions of 'different' responses for individual subjects by category. (Circles: adoptees; triangles: native French)

Within the group of adoptees, we compared the performance of subjects who had been reexposed to Korean since their adoption to that of adoptees who had had no contact with Korean. Figure 5 shows the average of 'different' responses for both groups according to Category. Post-hoc ttests revealed that the only category showing a significant effect of reexposure was DC3 $(\mathrm{t}(16)=2.3 p<.05)$. Figure 6 shows the correct discrimination scores for the DC3 pairs as a function of age of adoption for reexposed and not reexposed 
adoptees. The score did not increase with age of adoption.

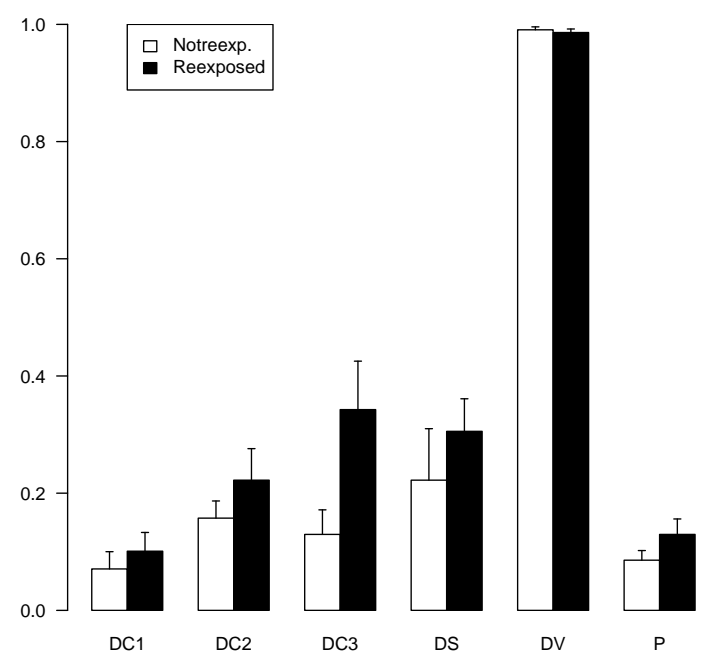

Figure 5. Scores of adoptees as a function of reexposure to Korean. The reexposed subjects performed better on the DC 3 category (tense-aspirated contrast for $\mathrm{p}$ and $\mathrm{k}$ ) than subjects who had not been reexposed to Korean since adoption

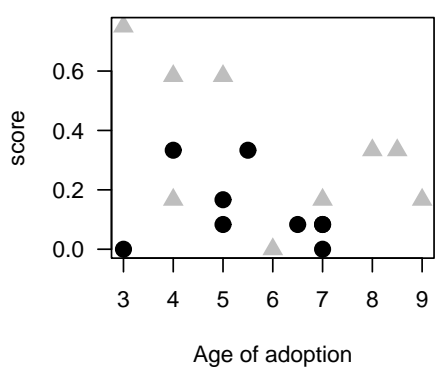

Figure 6. Scores in the DC3 category (tense vs. aspirated stops) for the adoptees as a function of age of adoption (triangles= reexposed to Korean; circles= not reexposed to Korean). )

\section{Discussion}

In this study we have found that early experience with language (even up until age nine) does not guarantee the availability of the attrited language's phonology later in life. Our results show that the Korean adoptees have become like native French speakers in their perception of Korean consonants, and quite unlike native Koreans.

In comparing those adoptees who had been reexposed to Korean through trips to Korea to those with no reexposure since adoption, we only found a small advantage for the reexposed subjects on the DC3 (tense-aspirated) category. This category is the easiest to distinguish as it involves a large difference in VOT. Such an advantage is minimal.
Our results differ from those obtained in other studies involving attrition of a childhood language where a clear advantage of childhood overhearers in phonetic perception has been found (Tees \& Werker, 1984; Au et al. 2002; Oh et al., 2003). Perhaps two fundamental differences between our population of adoptees and the populations in these studies can account for the discrepancy in results. The populations in these studies grew up in communities where some exposure to the attrited language presumably continued to occur throughout development, either from direct overhearing of the language (as one can imagine may be the case of Spanish in California) or through the persistence of the foreign language phonemes in the English of close family or community members. Our Korean adoptees were, on the contrary, completely severed from their home language and culture upon arrival in francophone Europe where Korean is not at all common; their exposure to Korean phonemes was therefore non-existant.

Another fundamental difference between our population and the ones in the above-mentioned studies is reexposure and formal instruction. The subjects in the previous studies seem to have willingly enrolled themselves in classes in order to relearn their attrited childhood language. Of our Korean adoptees, only half had been reexposed to Korean, mostly during short touristic trips to Korea. And of these subjects, only two had received language training lasting a few months. It is interesting to note that the only subject who was taking a Korean language class during three months prior to testing performed better on all contrasts than the group of adoptees. This suggests that extensive reexposure may be an essential factor in the recovery of phonetic knowledge, which may be present but diffi cult to retrieve. It is possible that extensive training, such as that administered by Logan et al. (1991) to Japanese learners of English on the /r/ and /1/ contrast, may be able to reactivate the dormant L1 in our adoptees. We are currently administering such a training programme, using Korean phonemes, to some of our Korean adoptees.

Such an example of fi rst language attrition may seem to challenge the critical period hypothesis for language acquisition. According to the original formulation of the hypothesis, "after the age of 10 or 12 , the general functional connections have been established and fi xed in the speech cortex" (Penfi eld, 1965; see also, Lenneberg, 1967). The present data, obtained with adoptees who arrived in France before age 10, cannot contradict this view. However, detrimental effects of age of acquisition have been noticed much before 10 years of age (e.g. Flege et al., 1995; Weber-Fox \& Neville, 1996; Pallier, Bosch \& Sebastian, 1997). According to some authors, there is a progressive decline in the ability to learn a language which can be noticed when exposure starts after age six (Long 1990; Pinker, 1994; but see Birdsong, 1999). If cortical networks subserving language processing become progressively crystallized during the fi rst ten years of life, then it is plausible that early exposure to a language should leave permanent traces in those networks. The present study and that of Pallier et al. (2003) did not fi nd evidence for traces of L1. If this outcome is confi rmed by further retrain- 
ing studies, this would indicate that there is still considerable plasticity in the language processing system until, at least, 910 years of age.

How can this notion be reconciled with data suggesting that, often, people who learn a second language after age 6 years do not reach full profi ciency? One possible explanation suggests that the effects of age of acquisition before the age of 10 , are not due to an irreversible decrease of neural plasticity with age, but are rather due to an increased stabilization of the neural network by the learning of L1. When exposure to L1 ceases, then the network could somehow 'reset' and L2 would be acquired fully. To test this hypothesis one would need to compare the performances in L2 of adopted subjects with that of immigrants who arrived in the foreign country at the same age but have continued using their L1. If the immigrants perform less well than the adoptees, then this would support the hypothesis of stabilization by L1. The present study leaves this issue open for debate.

In sum, the evidence of extensive attrition obtained in phonetic perception in this study corroborate the results obtained by Pallier et al. (2003) in brain imaging and by Ventureyra \& Pallier (in press) with respect to number series recognition. Thus, attrition in our population of Koreans adopted during childhood seems to have affected linguistic domains generally considered to be relatively resistant to attrition: phonology due to its early acquisition and number series due to their strong memory storage (Berko-Gleason, 1982). These results also extend the fi ndings of case studies in children undergoing L1 attrition (Nicoladis \& Grabois, 2002; Kaufman \& Aronoff, 1991; Turian \& Altenberg, 1991) implying that L1 attrition in children is more wide-spread and drastic than it is in adults, in whom attrition more likely reflects diffi culty in access to knowledge as opposed to a true 'disappearance of knowledge' from memory (Kopke \& Schmid, in press). Whether linguistic knowledge has truly disappeared or is extremely diffi cult to access in cases of childhood language attrition remains to be determined. The relearning experiments and some implicit memory tasks currently being tested on our population of Korean adoptees may shed some light on this important issue.

\section{References}

Ammerlaan, T. 1996. "You get a bit wobbly..." - Exploring bilingual lexical retrieval processes in the context of first language attrition. Unpublished Doctoral Dissertation, Nijmegen: Katholieke Universiteit Nijmegen.

Au, T. K., Knightly, L. M., Jun, S.-A. \& Oh, J. S. (2002) Overhearing a language during childhood. Psychological Science, 13(3), 238-243.

Berko-Gleason, J. (1982). Insights from child language acquisition for second language loss. In R. Lambert \& B. Freed (Eds.) The loss of language skills. Rowley, MA: Newbury House Publishers.

Birdsong, D. (1999) Second language acquisition and the critical period hypothesis. London: LEA.
De Bot., K., Gommans, P. \& Rossing, C. (1991) L1 loss in an L2 environment: Dutch immigrants in France. In $\mathrm{H}$. W. Seliger \& R. M. Vago (Eds.) First Language Attrition. Cambridge, UK : Cambridge University Press.

Flege, J. E., Munro, M. J., \& MacKay, I. R. (1995). Factors affecting strengh of perceived foreign accent in a second language. Journal of the Acoustical Society of America, $97,5,3125-3134$.

Hulsen, M. 2000. Language loss and language processing. Three generations of Dutch migrants in New Zealand. Unpublished Doctoral Dissertation, Nijmegen: Katholieke Universiteit Nijmegen.

Kaufman, D. \& Aronoff, M. (1991) Morphological disintegration and reconstruction in fi rst language attrition. In $\mathrm{H}$. W. Seliger \& R. M. Vago (Eds.) First Language Attrition. Cambridge, UK : Cambridge University Press.

Kopke, B. (2001) Quels changements linguistiques dans l'attrition de la L1 chez le bilingue tardif ? Travaux Neuchâtelois de linguistique, 34-35, 1-14.

Köpke, B. \& Schmid, M. (in press). Language attrition: The next phase. In M.S. Schmid, B. Köpke, M. Keijser \& L. Weilemar (Eds.) Proceedings of the International Conference on First Language Attrition, Amsterdam: John Benjamins.

Kuhl, P., Williams, K., Lacerda, F., Stevens, K \& Linblom, B. (1992) Linguistic experience alters phonetic perception in infants by 6 months of age. Science, 255, 606-608.

Lenneberg, E. (1967) The biological foundations of Language. New York: Wiley.

Logan, J. S., Lively, S. E. \& Pisoni, D. B. (1991) Training Japanese listeners to identify English /r/ and /1/ : A fi rst report. Journal of the Acoustical Society of America, 89(2), 874-886.

Long, M. (1990) Maturational constraints on language development. Studies in second language acquisition, 12, 251-285.

Major, R.C. (1992). Losing English as a fi rst language. The Modern Language Journal, 76, 190-208.

Maury, F. (1999) L'adoption interraciale. Paris : L'Harmattan.

Nicoladis, E. \& Grabois, H. (2002) Learning English and losing Chinese : A case study of a child adopted from China. The International Journal of Bilingualism, 6, 441-454.

Oh, J., Jun, S.-A., Knightly, L., \& Au. T. K. (2003) Holding on to childhood language memory. Cognition, 86, B53B64.

Pallier, C., Bosch, L., \& Sebastian-Gallés, N. (1997). A limit on behavioral plasticity in speech perception. Cognition, 64, 3, B9-B17. 
Pallier, C., Christophe, A., \& Mehler, J. (1997) Languagespecifi c listening.Trends in Cognitive Science, 1(4), 129132.

Pallier, C., Dehaene, S., Poline, J.-B., LeBihan, D., Argenti, A.-M, Dupoux, E. \& Mehler, J. (2003). Brain imaging of language plasticity in adopted adults : Can a second language replace the fi rst ? Cerebral Cortex, 13, 155-161.

Penfi eld, W. (1965). Conditioning the uncommited cortex for language learning. Brain, 88, 787-798.

Pinker, S. (1994). The language instinct. New York: Morrow and Co.

Polka, L. (1991) Cross-language speech perception in adults : Phonemic, phonetic and acoustic contributions. Journal of the Acoustical Society of America, 89(6), 29612977.

Seliger, H. W. \& Vago, R. M. (Eds.) (1991) First Language Attrition. Cambridge, UK : Cambridge University Press.

Strange, W. \& Jenkins, J. J. (1978) Linguistic experience and speech perception. In R.D. Walk \& H. L. Pick (Eds.) Perception and Experience, New York : Plenum.

Tees, R. C. \& Werker, J. F. (1984) Perceptual flexibility : Maintenance or recovery of the ability to discriminate nonnative speech sounds. Canadian Journal of Psychology, $38,579-590$.

Turian, D. \& Altenberg, E. (1991) Compensatory strategies of child fi rst language attrition. In H. W. Seliger \& R. M. Vago (Eds.) First Language Attrition. Cambridge, UK : Cambridge University Press.

Ventureyra, V.A.G. \& Pallier, C. (in press) In search of the lost language: The case of adopted Koreans in France. In M.S. Schmid, B. Köpke, M. Keijser \& L. Weilemar (Eds.) Proceedings of the International Conference on First Language Attrition, Amsterdam: John Benjamins.

Weber-Fox, C. M. \& Neville, H. J. Maturational Constraints on Functional Specializations for Language Processing: ERP and Behavioral evidence in Bilingual Speakers, Journal of Cognitive Neuroscience, 8, 3,231-256.

Werker, J. K. \& Tees, R. C. (1983) Developmental changes across childhood in the perception of non-native speech sounds. Canadian Journal of Psychology, 37, 278-286.

Werker, J. K. \& Tees, R. C. (1984) Cross-language speech perception : Evidence for perceptual reorganization during the first year of life. Infant Behaviour and Development, 7, 49-63. 